\title{
Perhaps the time has come
}

\author{
Alan BR Thomson MD PhD FRCPC FRCP FACG
}

A conflict of interest occurs in a situation in which professional judgment regarding a primary interest, such as research, education or patient care, may be unduly influenced by a secondary interest, such as financial gain or personal prestige. Conflicts of interest exist in every walk of life, including medicine and science. There is nothing inherently unethical in finding oneself in a conflict of interest. Rather, the key questions are whether one recognizes the conflict, and how one deals with it. Strategies include disclosing the conflict, establishing a system of review and authorization, and prohibiting the activities that lead to the conflict.

As gastroenterologists, we enjoy a high level of public respect for our knowledge, skills and professionalism. Our subspecialty is technically and intellectually demanding, and we enjoy a level of remuneration that places us at the upper end of the scale for internists. The patients, whom we have the privilege to care for, often have chronic diseases such as dyspepsia, inflammatory bowel disease or viral hepatitis. These conditions need to be treated with costly therapy, and this bring us into frequent and sometimes close interaction with the pharmaceutical industry. The need for our own as well as family practice colleagues' continued mediCal education (CME) or continue professional development (CPD) will also bring us to an interface with industry. As well, many gastroenterologists in institutional or private practice will be engaged in clinical research studies, often sponsored by the pharmaceutical industry. This relationship may be mutually beneficial, and it is of course the research by industry that brings to market the many therapeutic choices available to us to benefit our patients. Industry has been very generous in supporting the Canadian Association of Gastroenterology (CAG), the Canadian Digestive Health Foundation and the Canadian Journal of Gastroenterology, to mention just a few of the many sponsorships. This Viewpoint pleads for each of us to respect our own personal need to continue to be vigilant as professionals to remain free from undue industry influence, to maintain our professional integrity in expressing our views at CME/CPD events and on advisory boards, and to resist the temptation of relying too heavily on industrial sponsorship for our professional educational events. We must seek ways to reconcile the commercial needs of the pharmaceutical industry, and our own needs to be fair, balanced, and above all, independent.

In the worlds of medicine and business, transparency remains the centerpiece of honesty and just plain old-fashioned decency. Physicians traditionally have a special role, providing care for our fellow human beings. Our decisions for care are based on knowledge and judgment, rendering patients and their family members truly informed about available diagnostic and therapeutic options. Physicians function under the ideal that their recommendations will be informed, humane and honest. Physicians respect the subtle balance between evidence-based medicine, tempered with our own experience, and knowledge of our patients' unique psychosocial situations, as well as their personal choices.

Recently the physicians' time honoured position has been bombarded, so often by subconscious pressures of subliminal messages, by marketing forces placed on each and every one of us by the pharmaceutical and equipment industries. In our own specialty of gastroenterology, this is apparent in the "PPI Wars", the high stakes marketing of high volume, high price products in which the differences between the "-prazoles" is often very small. With almost a half billion dollars of annual sales of the prazoles - equivalent to $\$ 15$ for each man, woman and child in Canada each year! - the stakes are truly very high. Certainly there is similar strenuous competition in other areas such as the interferons, the coxibs and the bisphosphonates. Oh, you say, I know all about marketing methods, and I am above that; I know how to sort out the wheat from the chaff; I know how to apply evidence-based medicine, make my therapeutic choices based only on scientific data for what is best for my patient; I am immune from all this commercialization. I hope you are right.

Certainly the pharmaceutical industry in Canada has brought many benefits to our patients, with innovative effective therapies. Industry has been very generous in sponsoring clinical studies and research in Canada, in supporting our professional organizations, our fellowship programs, our Foundation, our Journal - and sometimes even our own travel to meetings. But it is in the very competitiveness of the industry, and the marketing of what are sometimes small therapeutic differences, that undue pressure may be placed on us, where there is the greatest need for moderating the need for industry to sell, and where we must be critically aware of our own need not to be influenced. We need a better process of reconciling the reasonable marketing realities of industry, and the need of our subspecialty and ourselves to maintain independence, integrity, transparency and social justice.

Please stop to ponder. As noted by Rakatansky in a recent thoughtful paper in Alimentary Pharmacology and Therapeutics (1), there are multiple pressures placed on all of us, the mar-

Correspondence: Dr Alan BR Thomson, \#205 College Plaza, 8215 - 112 Street, Edmonton, Alberta T6G 2C8. Telephone 780-492-6490,

fax 780-492-7964, e-mail alan.thomson@ualberta.ca

Received and accepted September 9, 2003 
keting efforts of the pharmaceutical industry do work (2), and we are much less immune than we may choose to believe. We all have the potential to be influenced, to be biased. Consider some examples. The person who has been a consultant for a pharmaceutical company and continues to receive substantial research funding, who presents Medical Grand Rounds on the company's new expensive biological while failing to provide fair balance about adverse effects; the medical resident presenting subspecialty rounds discussing the findings of a major clinical trial, who fails to consider the negative aspects of the study, and when asked about this unexpected deficiency, confesses "the drug rep' was in the audience and I didn't want to embarrass her with a negative comment, especially after she bought us all free lunch for the rounds." Is our assisting in a clinical trial, especially a phase IV study, simply a way to get us to use a drug and thereby to obtain our prescription business? Consider the person who receives research funding or ongoing support for local educational events from a specific company and attempts to provide a balanced report at medical Grand Rounds or on a Therapeutic Committee with regard to that company's novel agent. Certainly there may be a sense of obligation to be at least not contentious about that company's product, if not overtly favourable to it. Some resist the pressure and some succumb to it, all in varied degrees, but the pressure is there nonetheless.

Our own annual meeting of the CAG is very heavily subsidized by the pharmaceutical industry. Are we prepared to have less sponsorship, and more financial independence, but at the cost of self-supporting registration fees? How many provincial GI societies need to reflect on their dependence upon industry? Consider the colleague who was abruptly removed from an industry advisory board because he/she dared to give an honest legal opinion to a generic company - this highlights the punishment for stepping outside the corporate expectation of unfailing, unquestioning loyalty. Have we as physicians lost our ability to express an honest opinion about a product, or a study, or a marketing approach? Is the provision of an honorarium to speak at a CME conditional on entering the grey zone, perhaps quoting only the studies supporting the sponsor's product? We must continue to work hard to ensure that our own Canadian Digestive Health Foundation soon becomes funded by more than one major company. That effort is laudable.

What might be some specifics, some future deliverables for ourselves personally, our professional organizations, and our academic leadership? The American College of Physicians (3) and the American Medical Association Council on Ethical and Judicial Affairs $(4,5)$, have policies on the issue of the ethical interaction of physicians and the pharmaceutical industry. The CAG adheres to the Canadian Medical Association (CMA) Code of Ethics, which has been updated recently (all policies of the CMA are available electronically through CMA online at www.cma.ca). The CAG has also recently adopted a policy regarding interactions with the pharmaceutical industry, published in the Canadian Journal of Gastroenterology (16:36$38,2002)$. But perhaps there is a need to go even further, since the need for a strong and clear position on conflicts of interest is necessary, since the ethical issues are important for both patients and professionals in the mutual relationship that is the foundation of our Canadian health care system. We should ask "Are we willing to let patients (or payers) know all about what the pharmaceutical industry does for us?" We need to be transparent about the benefits we receive individually and collec- tively. The pharmaceutical industry is very competitive, and there is the potential for large profits, but also for large losses. Physicians themselves need to continue to set the ethical standards needed to protect patients with their own high professional integrity. We are involved in the very issue of social justice; we physicians who are among the most advantaged and privileged in our society benefit from the social and entertainment aspects of marketing - as well as of course the very legitimate and essential aspects of the educational component. We need to strive to obtain an optimal level of balance and fairness.

A number of thoughtful recent papers remind all of us of the potential hazards of participating in clinical trials sponsored by industry (6-11). Perhaps, as suggested by Rakatansky (1) and other authors (12-14), the time has come "...to create a uniform standard which might be adapted by different institutions." The time has come when we need to remind ourselves that payment to the physician for arranging for our patient to participate in a clinical trial needs to be for the work done, not just a 'finder's fee' for referral of the patient into the study (15). Those remaining in academic medicine continue to function under the umbrella of 'publish or perish', and must constantly reflect on the need to ensure that we have the freedom to publish the results of clinical trials, even if the results are not favorable to the industry sponsor. Unequivocal standards have been set on this point by a number of bodies, including the International Committee of Medical Journal Editors $(14,16)$, the Association of American Medical Colleges (4), and the American Association of University Professors (17). Let us not lag a decade behind our American colleagues; our own professional organizations need to address these issues and develop potential 'made in Canada solutions' (18).

The Canadian Journal of Gastroenterology, of which I am a proud co-founder 15 years ago, needs to continue to have a strong disclosure policy for possible conflicts of interest by both authors and reviewers. It is perhaps the time for the Canadian Journal of Gastroenterology to endorse the standards of the International Committee of Medical Journal Editors, and to raise the bar to declare potential conflicts of interest on the part of journal reviewers as well as contributors. The editor and editorial board are doing much to move in this direction.

Perhaps we at the CAG/Canadian Association for the Study of the Liver need to consider the stern adviCe of Pellegrino and Relman (19): "...the professional medical society should not seek or accept support from companies that sell health care products or services", and we need to reevaluate the terms by which we accept support from industry. These are not welcome words at the time when we move ahead to organize what promises to be the most brilliant ever, 2005 World Congress of Gastroenterology in Montreal. Yet, surely that is the very reason that we must thoughtfully reflect on the potential conflicts of interest in our medical organizations. Perhaps we should use our own uniquely Canadian perception of the importance of social justice to eliminate the excess, the freebees, the perks and gadgets and free tickets, and to use more of the profits from our meetings to help develop health care and professional development in countries that could use our assistance.

As one of our senior gastroenterologists and highly respected clinicians and educators said to me recently in confidence with regards to physician's interactions with the pharmaceuti- 
cal industry: "we all prostitute ourselves sometimes, we all skate on pretty thin ice". Is it not time for us to be like Caesar's wife, to be purer than pure, to re-examine how we are pressured by industry, how our opinions are being influenced, how we - and our professional organizations - are at risk of being unduly influenced? Is it not time for us to regain our independence, our honour, our peace of mind? Who will be the first to step back?

This is an important time in the history of our subspecialty, our profession, and perhaps even in the life of our own history. I ask for reflection, thoughtful discussion, for honesty and transparency. I ask that we pause to listen to our own conscience. I ask that we listen to the words of Ratatansky (1):

"It is the responsibility of doctors, individually and collectively, to utilize these products [of industry] in the best interests of patients....Individual physicians and organizations should be knowledgeable about pertinent guidelines, evaluate them carefully and, in the absence of a cogent, publicly disclosed reason not to do so, endorse and follow them."

Perhaps the time has come.

ACKNOWLEDGEMENTS: I wish to express my sincere appreciation to over 30 persons for the honest, frank and helpful comments I received during the preparation of this Viewpoint - past presidents, current executive members, senior physicians, ethicists and concerned citizens. While not all agreed with my point of view, it was through this healthy exchange, discussion and reflection that beneficial change will occur one step at a time - to each of you, thank you. In the spirit of transparency, the author is happy to disclose the following participation on advisory boards, speaker panels, and/or receiving research or travel support from the following: Abbott, Altana/BYK/Solvay, AstraZeneca, Axcan, CAG, CCFC, CIHR (MRC), CSCI, Ferring, Glaxo Smith Kline, Janssen-Ortho, Merck, MIRF, Negma-Lerads, Novartis, OMGE, Pfizer/Pharmacia, Proctor \& Gamble, Royal College of Physicians and Surgeons, Scherring, SCI and TAP.

\section{REFERENCES}

1. Rakatansky H. Review article: Gastroenterology and the pharmaceutical industry. Aliment Pharmacol Ther 2002;16:1859-66.

2. Gammage J, Stark K. Under the influence. Philadelphia Inquirer (Magazine Section) 2002; March 15.

3. Coyle SL. Physician-industry relations. Part 1: individual physicians. Ann Intern Med 2002;136:396-402.

4. Task Force on Financial Conflicts of Interest in Clinical Research Protecting Subjects. Preserving Trust, Promoting Progress. Policy Guidelines for the Oversight of Individual Financial Interests in Human Subjects Research. Washington DC: Association of American Medical Colleges, 2001.

5. The Council on Ethical and Judicial Affairs of the American Medical Association. Guidelines on gifts to physicians from industry: an update. Food Drug Law J 2001;56:27-40.

6. Bodenheimer T. Uneasy alliance: Clinical investigators and the pharmaceutical industry. N Engl J Med 2000;342:1539-44.

7. Boyd EA, Bero LA. Assessing faculty financial interests with industry. J Am Med Assoc 2000;284:2209-14.

8. DeAngelis CD, Fontanarosa PB, Flanagin A. Reporting financial conflicts of interest and relationships between investigators and research sponsors. J Am Med Assoc 2001;286:89-91.

9. Kelch RP. Maintaining the public trust in clinical research. N Engl J Med 2002;346:285-7.

10. Lo B, Wolf LE, Berkeley A. Conflict of interest policies for investigators in clinical trials. N Engl J Med 2000;343:1616-20.

11. Morin K, Rakatansky H, Riddick FA Jr, et al. Managing conflicts of interest in the conduct of clinical trials. J Am Med Assoc 2002;278:78-84.

12. Campbell EG, Louis KS, Blumenthal D. Looking a gift horse in the mouth. Corporate gifts supporting life science research. J Am Med Assoc 1998;279:995-9.

13. Bero LA. Disclosure policies for gifts from industry to academic facility. J Am Med Assoc 1998 279:1031-2.

14. International Committee of Medical Journal Editors. Sponsorship, Authorship, and Accountability, 2000, <www.icmje.org/sponsor. $\mathrm{htm}>$ (Version current at September 17, 2003).

15. Opinion 6.03. AMA Code of Medical Ethics. Chicago, IL: American Medical Association, 2002.

16. Davidoff F, DeAngelis CD, Drazen JM, et al. Sponsorship, authorship, and accountability. J Am Med Assoc 2001;286:1232-4.

17. Statement on Corporate Funding of Academic Research. Washington, DC: American Association of University Professors, 2001.

18. Lemmens T, Singer PA. Bioethics for clinicians: 17. conflict of interest in research, education and patient care. Can Med Assoc J 1998;159:960-5.

19. Pellegrino ED, Relman AS. Professional medical associations ethical practical guidelines. J Am Med Assoc 1999;282:984-6. 


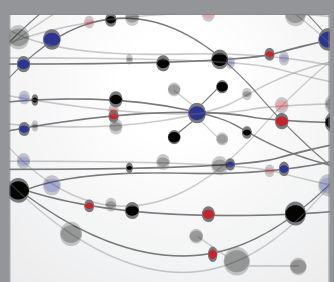

The Scientific World Journal
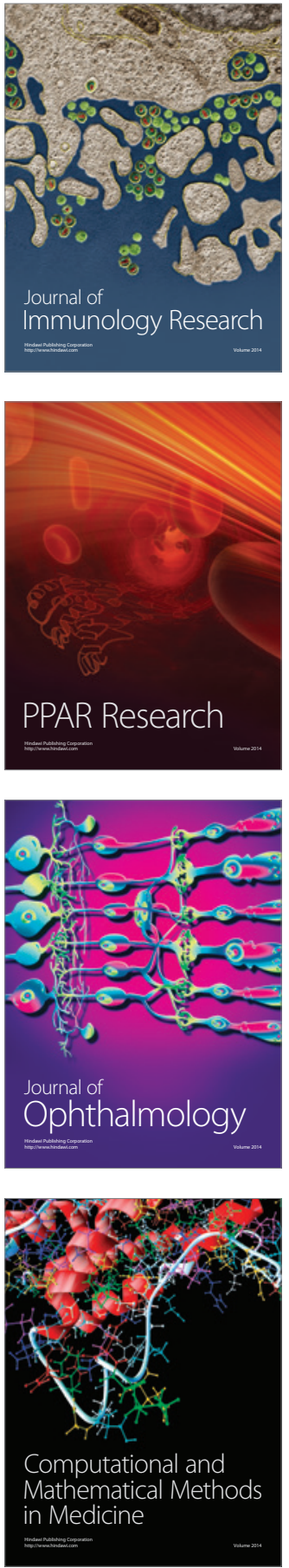

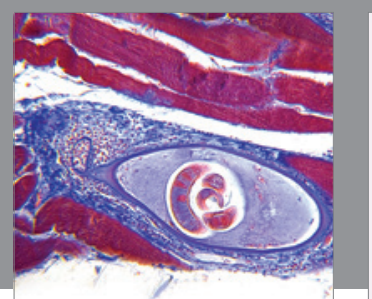

Gastroenterology Research and Practice

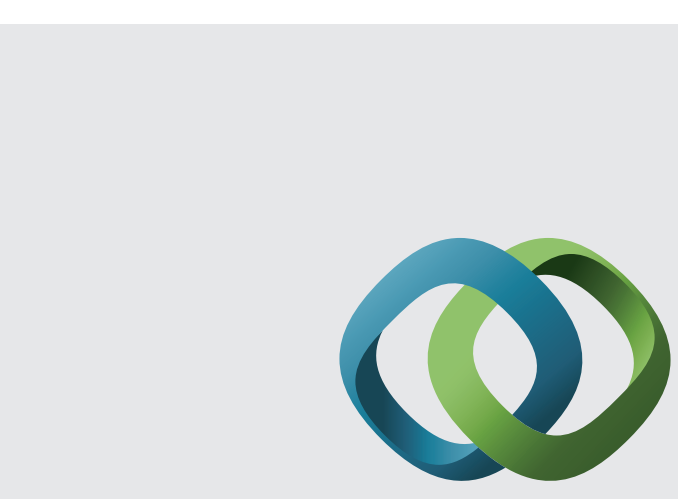

\section{Hindawi}

Submit your manuscripts at

http://www.hindawi.com
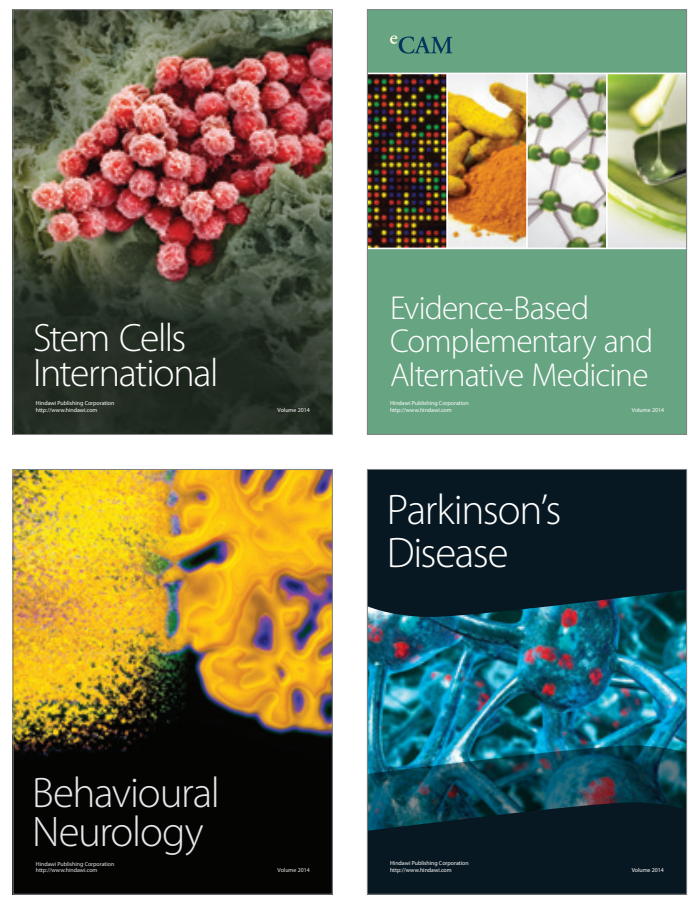
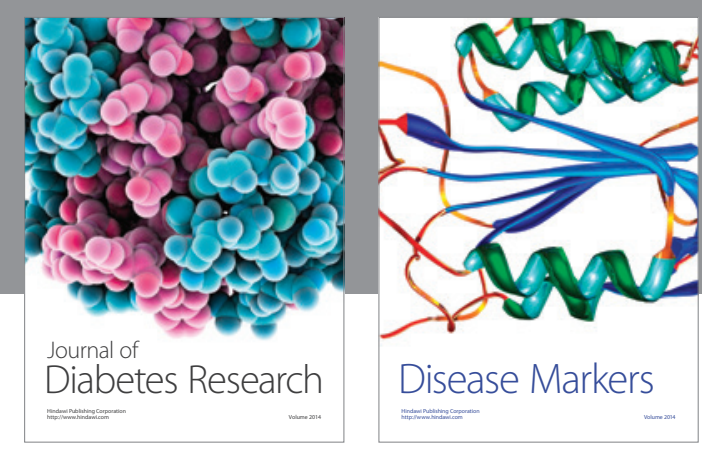

Disease Markers
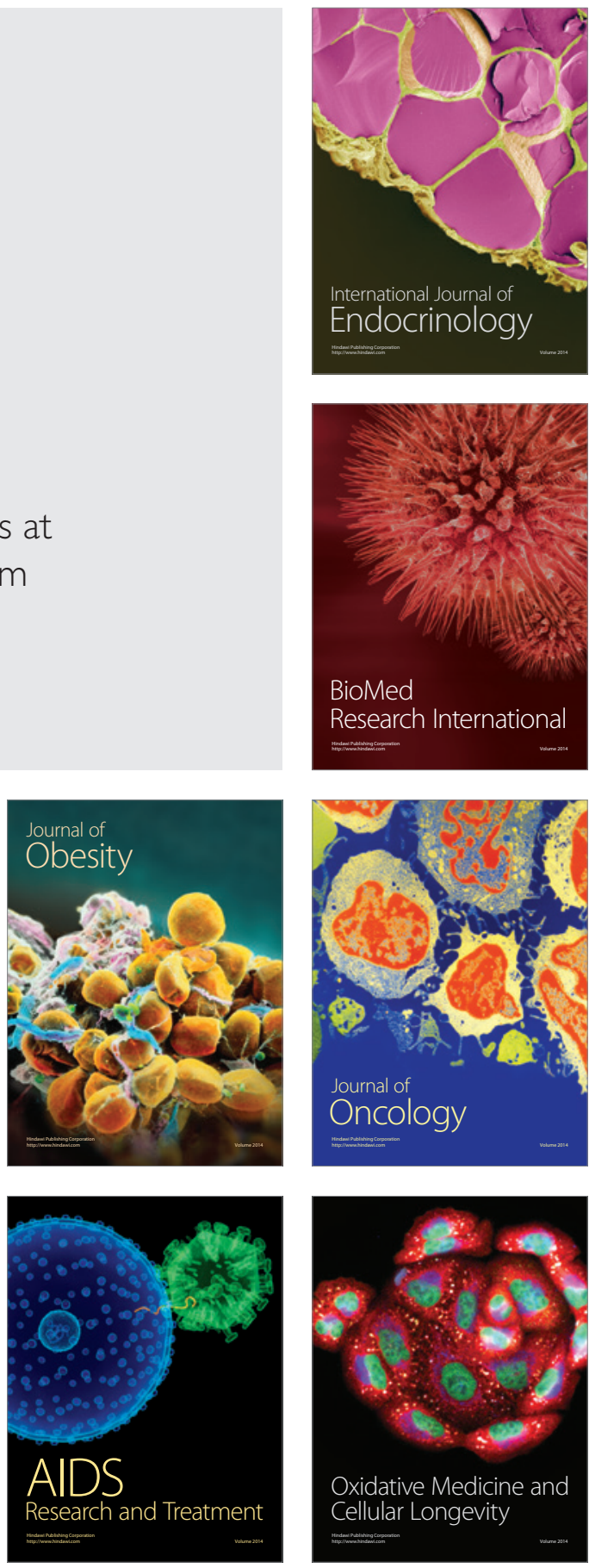